\title{
La dieta rica en grasas mostró una débil asociación con enfermedad coronaria
}

Ascherio A, Rimm E, et al. Dietary fat and the risk of coronary heart disease in men: cohort follow up study in the United States. BMJ 1996;313:84-90

\section{Objetivo}

Examinar la asociación entre la ingesta de grasas con sus distintos componentes, y la incidencia de enfermedad coronaria en hombres a partir de la edad media de la vida.

\section{Diseño}

Estudio prospectivo de cohortes.

Lugar

Estados Unidos.

\section{Participantes}

43757 hombres, profesionales de la salud; sin enfermedad coronaria, cerebrovascular, vasculopatía periférica y diabetes al comienzo del estudio.

\section{Evaluación de factores de riesgo}

Cuestionario basal sobre dieta y factores de riesgo coronario, seguimiento a seis años con evaluaciones cada dos años. Se separan cinco grupos (quintilos), de acuerdo a la cantidad diaria ingerida de ácidos grasos saturados, colesterol, ácidos grasos totales, ácido linoleico y linolénico.

\section{Medición de resultados}

Incidencia de enfermedad coronaria. Eventos fatales y no fatales.

\section{Resultados principales}

La asociación de la ingesta de los distintos compo- nentes de las grasas con los eventos coronarios fatales y no fatales fue muy débil especialmente cuando se toma en cuenta la ingesta de fibras. Comparando los hombres en el quintilo más alto de ingesta de grasas saturada con el más bajo, el riesgo relativo de infarto agudo de miocardio fue de 1.22 (95\% IC 0.96 a 1.56 ), y para enfermedad coronaria fatal de 2.21 (95\% IC 1.38 a 2.74). Una vez realizado el ajuste por ingesta de fibras los resultados pierden significancia estadística. El análisis de la ingesta de colesterol, grasa total y ácido linoleico mostró iguales resultados.

La ingesța de ácido linolénico se asoció negativamente con el riesgo de infarto agudo de miocardio luego de ser ajustada por ingesta de fibras, factores de riesgo e ingesta total de grasas $0.41(95 \%$ IC 0.21 a 0.8 ). No tuvo asociación significativa con enfermedad coronaria fatal.

\section{Conclusiones}

En este estudio la relación entre la ingesta de grasas y la enfermedad coronaria es débil. Los resultados son consistentes en todos los parámetros considerados, siempre el riesgo relativo es significativo cuando el ajuste se realiza únicamente por edad, pero al tomar los factores de riesgo coronario e ingesta de fibras deja de serlo. Los resultados de este estudio, muestran una importante asociacion entre la dieta y el riesgo de enfermedad coronaria. Se observa que el efecto de la grasa saturada en el riesgo de enfermedad coronaria es mucho menor a la reportada por otros trabajos internacionales que probablemente estén influidos por otros factores. Los beneficios en reducir la ingesta grasa y de colesterol son modestos, a menos que se acompañen de un mayor consumo de comidas ricas en fibra.

\section{Comentario}

La relación entre niveles elevados de colesterol y desarrollo de enfermedad coronaria ha sido ampliamente documentada. El estudio Framingham y el Multiple Risk Factor Investigation Trial (MRFIT) siguieron gran cantidad de pacientes por largo tiempo, pero brindaron escasa información sobre dieta. Sin embargo enfatizan que la mortalidad coronaria esta relacionada tanto con el nivel de colesterol como con la ingesta diaria de grasas. Posteriormente se observó que la grasa saturada era la más peligrosa en la incidencia de enfermedad coronaria, pero se encontraron importantes excepciones al estudiar distintas poblaciones. Es razonable pensar que existen otros factores todavía no identificados o incompletamente estudiados. En este contexto los resultados de este estudio son particularmente interesantes. Un requisito importante para postular causalidad es la relación dosis respuesta, (por ejemplo mayor ingesta de grasas ma- yor riesgo de IAM, muerte súbita). En este estudio aun comparando los quintilos extremos, con mayor diferencia en la ingesta y mayor riesgo, no se observan aumento de eventos al ajustar por factores de riesgo e ingesta de fibras. Esto debilita mucho la hipótesis causal. Sería interesante saber exactamente cuánto es el efecto de protección o riesgo de una mayor o menor ingesta de fibras. No queda claro tanto en este estudio como en otros en qué cantidad y en qué forma resultan más adecuadas la ingesta de fibras para obtener mayor protección. Resultaría de importancia seguir a esta cohorte un tiempo más prolongado y analizar por separado aquellos con colesterol elevado. Las recomendaciones internacionales actuales aconsejan eliminar la grasa saturada de la dieta y reemplazarla por hidratos de carbono presentes en las fibras (vegetales, legumbres, frutas). Según los hallazgos de este estudio el énfasis debería hacerse más en aumentar la in- gesta de fibras que en disminuir la ingesta de grasas.

\section{Dr Augusto Granel \\ Unidad de Medicina \\ Familiar y Preventiva \\ Hospital Italiano de Buenos Aires}

Referencias

1.Kannel WB, Castelli WP, Gordon T, Mc Namara PM.Serum cholesterol, lipoproteins, and the risk of coronary heart disease. Ann Intern Med 1971:74:1-12

2.Neaton JD, Blackburn H,et al.Serum cholesterol level and mortality findings for men 3.screened for the Multiple Risk Factor Intervention Trial Arch Intern Med 1992;152 4.Levine GN, Keaney JF, Vita JA.Cholesterol reduction in cardiovascular disease.Clinical benefits and possible mechanisms. N Engl J Med 1995;332:512-521 5.Rimm EB, Ascherio A, Giovanucci E.et al.Vegetable, fruit, and cereal fiber intake and risk of coronary heart disease among men. JAMA 1996;275:47-51

6. Expert Panel on Detection Evaluation and Treatment of High Blood Cholesterol in Adults. Summary of the second report of the National Cholestrol Education Program (NCEP) Expert Panel. JAMA 1993;269:3015-23 